\title{
QSpec: online control and data analysis system for single- cell Raman spectroscopy
}

Single-cell phenotyping is critical to the success of biological reductionism . Raman-activated cell sorting (RACS) has shown promise in resolving the dynamics of living cells at the individual level and to uncover population heterogeneities in comparison to established approaches such as fluorescence-activated cell sorting (FACS). Given that the number of single-cells would be massive in any experiment, the power of Raman profiling technique for single-cell analysis would be fully utilized only when coupled with a high-throughput and intelligent process control and data analysis system. In this work, we established QSpec, an automatic system that supports high-throughput Raman-based single-cell phenotyping. Additionally, a single-cell Raman profile database has been established upon which datamining could be applied to discover the heterogeneity among cells under different conditions.

To test the effectiveness of this control and data analysis system, a sub-system was also developed to simulate the phenotypes of single-cells as well as the device features. 


\section{QSpec: online control and data analysis system for single-cell Raman spectroscopy}

\section{Lihui Ren, Xiaoquan Su, Yun Wang, Jian Xu, Kang Ning*}

CAS Key Laboratory of Biofuels and Shandong Key Laboratory of Energy Genetics, Bioinformatics Group of SingleCell Center, Qingdao Institute of Bioenergy and Bioprocess Technology, Chinese Academy of Sciences, Qingdao, Shandong, P. R. China, 266101

*Corresponding author. Tel: +86-0532-80662624; Fax:+86-0532-80662654; Email: ningkang@qibebt.ac.cn 


\begin{abstract}
Single-cell phenotyping is critical to the success of biological reductionism. Raman-activated cell sorting (RACS) has shown promise in resolving the dynamics of living cells at the individual level and to uncover population heterogeneities in comparison to established approaches such as fluorescenceactivated cell sorting (FACS). Given that the number of single-cells would be massive in any experiment, the power of Raman profiling technique for single-cell analysis would be fully utilized only when coupled with a high-throughput and intelligent process control and data analysis system. In this work, we established QSpec, an automatic system that supports high-throughput Raman-based single-cell phenotyping. Additionally, a single-cell Raman profile database has been established upon which data-mining could be applied to discover the heterogeneity among cells under different conditions. To test the effectiveness of this control and data analysis system, a sub-system was also developed to simulate the phenotypes of single-cells as well as the device features.
\end{abstract}




\section{Introduction}

All organisms on earth, including bacteria, plants and animals, derive from single-cells. Genetically identical parent cells can produce cells with different functions due to the intrinsic variation among the individual offspring cells in gene expression and gene regulation. Microbiologists are specifically interested in single-cell techniques because most microorganisms ( $>99 \%)$ have not yet been cultured in the lab. These uncultivated microorganisms contain a large amount of functional genes and play crucial roles in natural ecosystems through various ways such as global warming, food security (through maintaining soil health and promoting plant growth), and environmental bioremediation .

The monitoring of microbial single-cells in vivo during the time course is an effective method to analyze the adaptation of a population to changing conditions, such as nutrient supply or stress exposure. Notwithstanding culminating evidences for varies adaptation diversities among individual population members, such endeavors have only been undertaken recently due to enormous technical challenges. Regardless of these obstacles, such studies hold great promise to provide substantial new insight into fundamental physiological processes in microorganisms as well as to accelerate the development of superior strains for industrial biotechnology.

Single-cell technologies, such as FACS analysis and the more recently developed RACS, are capable of detecting phenotypic heterogeneities in cellular population. Raman spectroscopy is an especially powerful analytical technique which has already been used in the study of single-cells. Raman spectroscopy is based on inelastic scattering of photons following their interaction with vibrating molecules of the sample. During this interaction, photons transfer (Stokes)/receive (AntiStokes) energy to/from molecules as vibrational energy. Thus, the energy change of the scattered photons corresponds to the vibrational energy levels of the sample molecules. For more detailed description of the physics of the Raman spectroscopy please refer to . Raman micro-spectroscopy can provide useful biochemical information regarding live cells, therefore has a wide application area 
including environment monitoring, healthcare, bioenergy, etc.

Recently, single-cell based Raman spectroscopy profiling (a light scatter analysis technique) has become highly appropriate at resolving the dynamics of cells at individual level by recording and comparing single-cell Raman spectra, yet the discrimination power of the Raman profiles is not particularly strong at distinguishing marginally different phenotypes. Nevertheless, RACS has several advantages over the classical fluorescence-based sorting. It can survey natural microbial communities or study gene expression variance in cells of the same genotype without artificial interference such as external tagging of cells or fluorescent protein insertion .

The RACS system automates the delivery, manipulation, analysis and sorting of single-cells from a continuous flow of cell samples. It enables the separation of cells according to their intrinsic chemical 'fingerprint' with minimal pre-treatment, thus cells are potentially viable after sorting . The isolated cells can then be further processed on a chip for cultivation or DNA amplification . Tweezers or microfluidic chips-based techniques combined with Raman micro spectroscopy could be used for tumor identification, cancer recognition and stem cell research, etc. Given that the number of singlecells to be analyzed and isolated would be massive in most experiments, the power of Raman profiling techniques for single-cell analysis would be fully utilized only with the accompany of high-throughput and intelligent online control and data analysis system.

In this work, we describe our approach for RACS system intelligent control and high-throughput data analysis in the following order: (1) Establishment of an automatic high-throughput process control system QSpec (http://www.computationalbioenergy.org/qspec.html) that could support the full cycle of single-cell phenotyping: instrument control (including RACS platform control and microfluidic device control), single-cell image analysis, single-cell Raman profiling, single-cell profile comparison, etc. (2) Based on this system, a single-cell Raman profile database was established based on which some database search and data-mining works were performed to discover the heterogeneity among cells under different conditions and at different time-points during differentiation. (3) To test the 
effectiveness of the whole control and data analysis system, we had also created a simulation system which can simulate single-cell features as well as device features, and tested the QSpec system with it. (4) The whole QSpec system is put to test on the prototype of the real single-cell Raman spectrum analysis platform. QSpec is an easy-to-use, fully-customizable, memory-efficient and fast software package that could be run on a desktop computer.

\section{Materials and Methods}

The QSpec software system is designed to be coupled with the RACS system for single-cell manipulation. Therefore, the RACS hardware is the foundation based on which QSpec software is designed. Fig. 


\section{Figure 1}

Schematic representation of RACS set-up.

Figure 1: Schematic representation of RACS set-up.

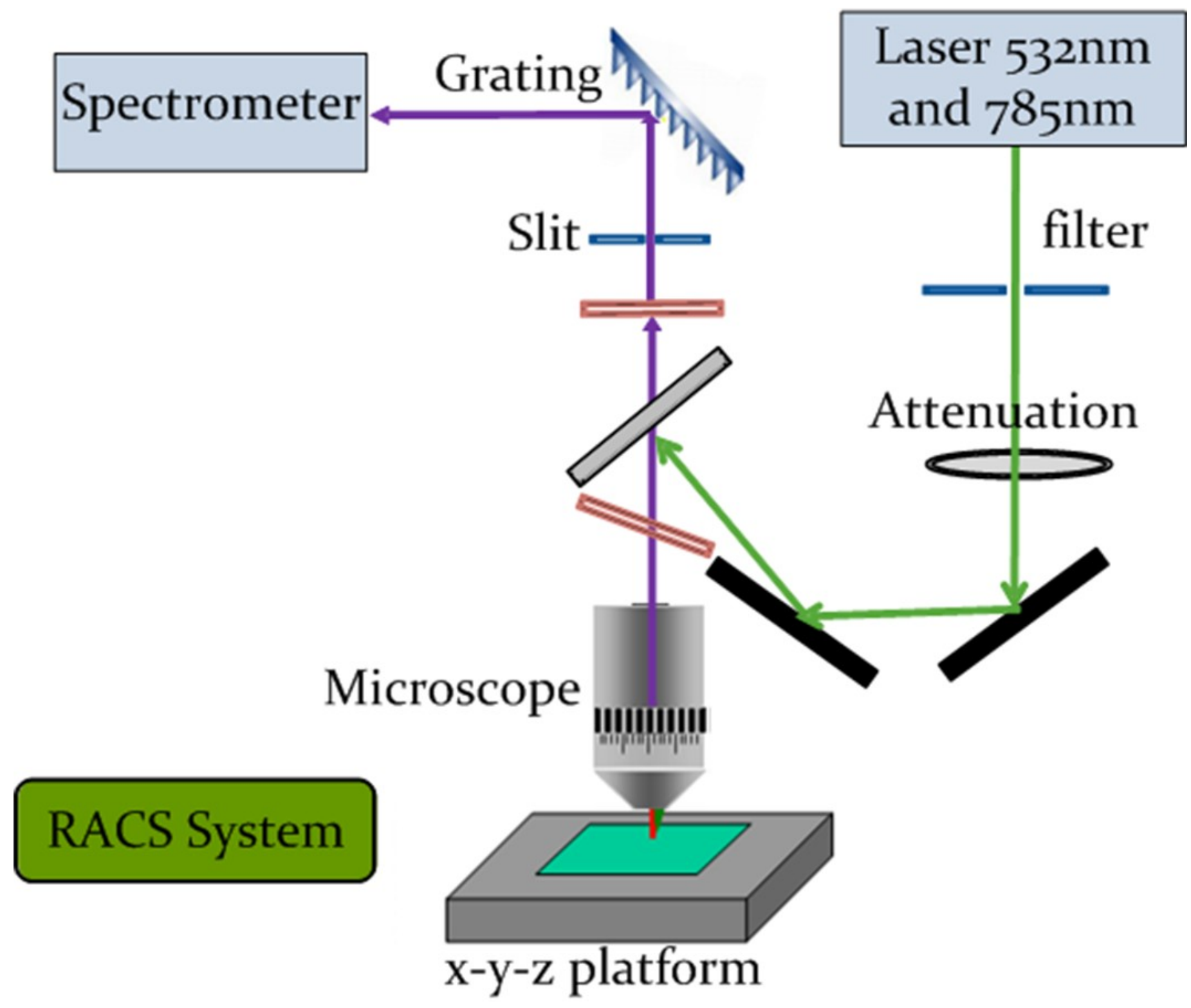




\section{Figure 2}

\section{Framework of QSpec}

Figure 2: Framework of QSpec. (A) Instrument Control, (B) Image Analysis, (C) Raman Profiling, (D) Database Update and (E) Database Search.

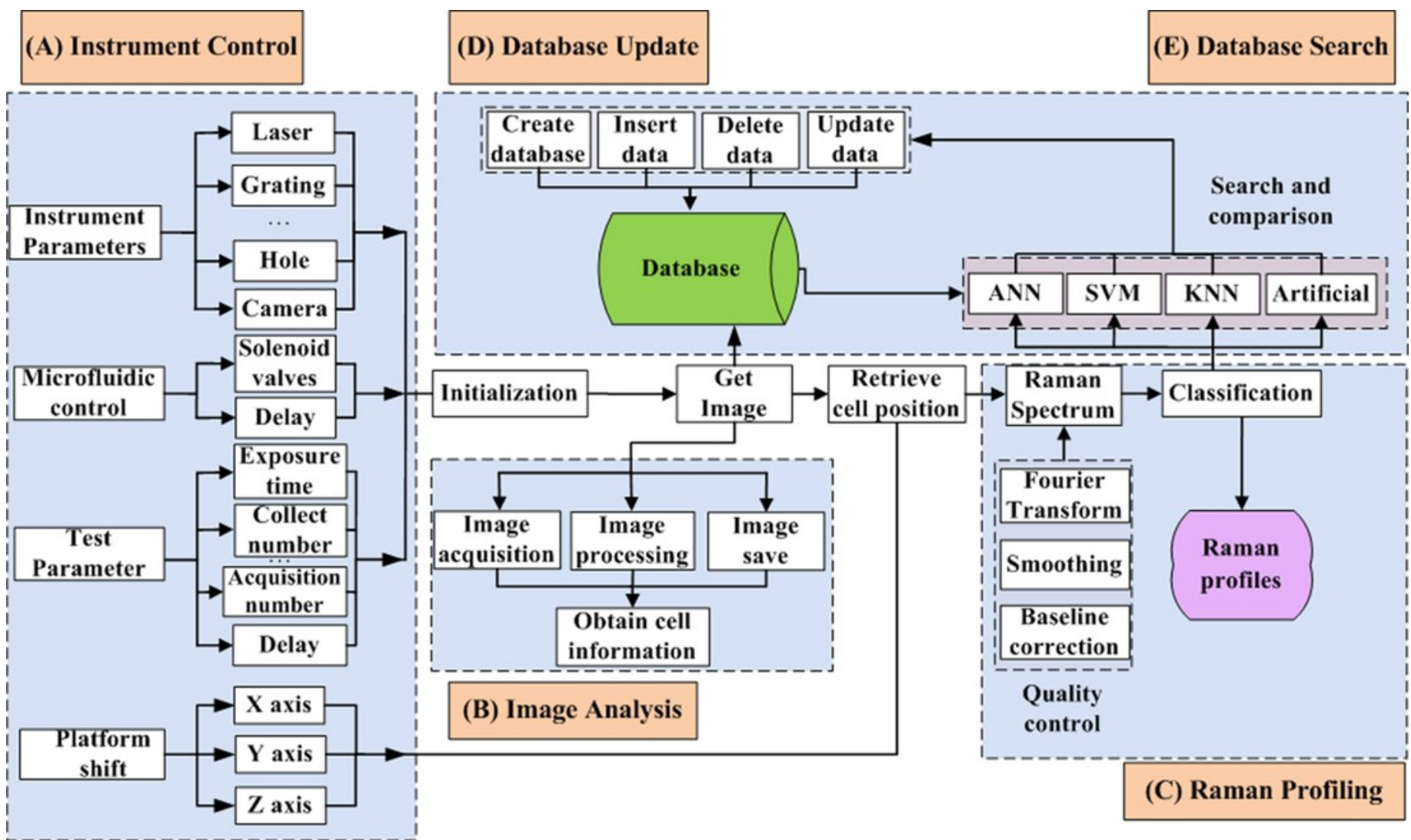




\section{Figure 3}

Screenshot of user interface for QSpec.

Figure 3: Screenshot of user interface for QSpec. The single-cell entry in the list, its coordinate, its image and the Raman spectrum were shown on the same screen.

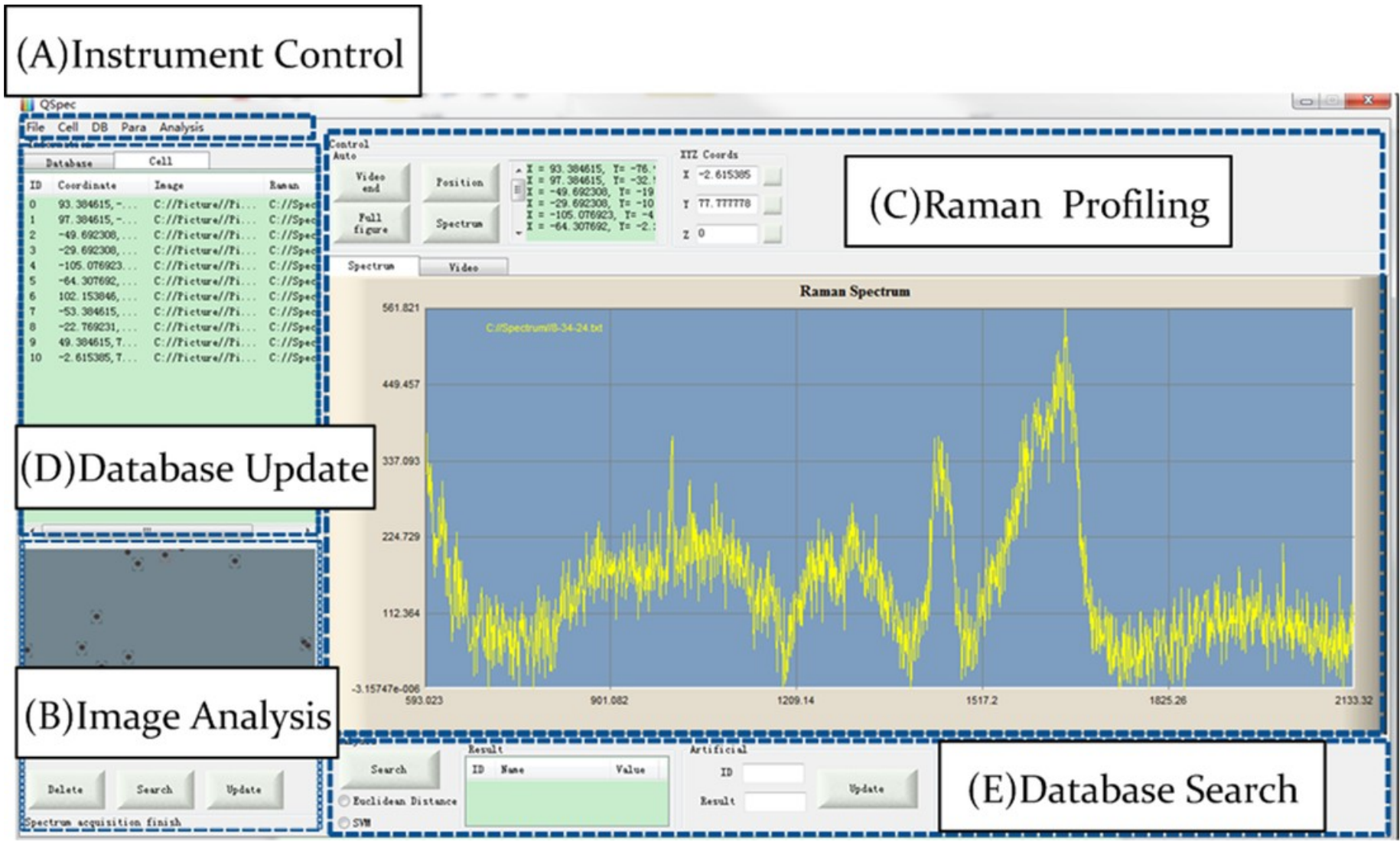




\section{Figure 4}

The instrument control parameter setting interface for (A) RACS platform control and (B) microfluidic device control.

\section{Figure 4: The instrument control parameter setting interface for (A) RACS platform} control and (B) microfluidic device control. In (B), the cell sorting is started based on single-cell Raman spectra, and the electromagnetic valve could be turned on and off for cell sorting if (i) the ratio of one peak intensity over another is greater than a threshold as defined or (ii) the difference of one peak intensity minus another is greater than a threshold as defined (as annotated in blue rectangles).

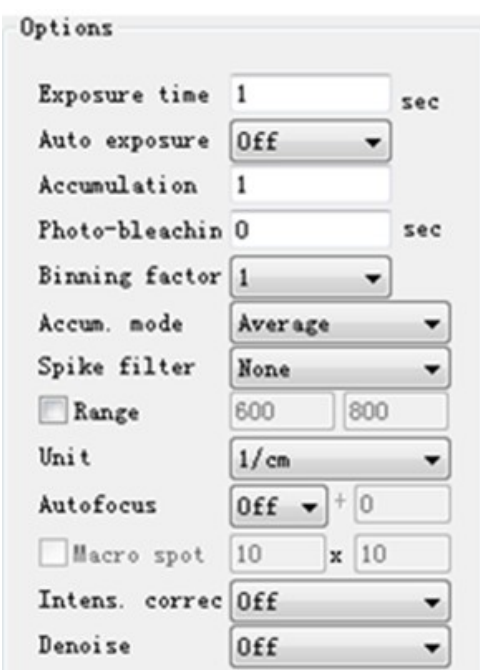

(A)

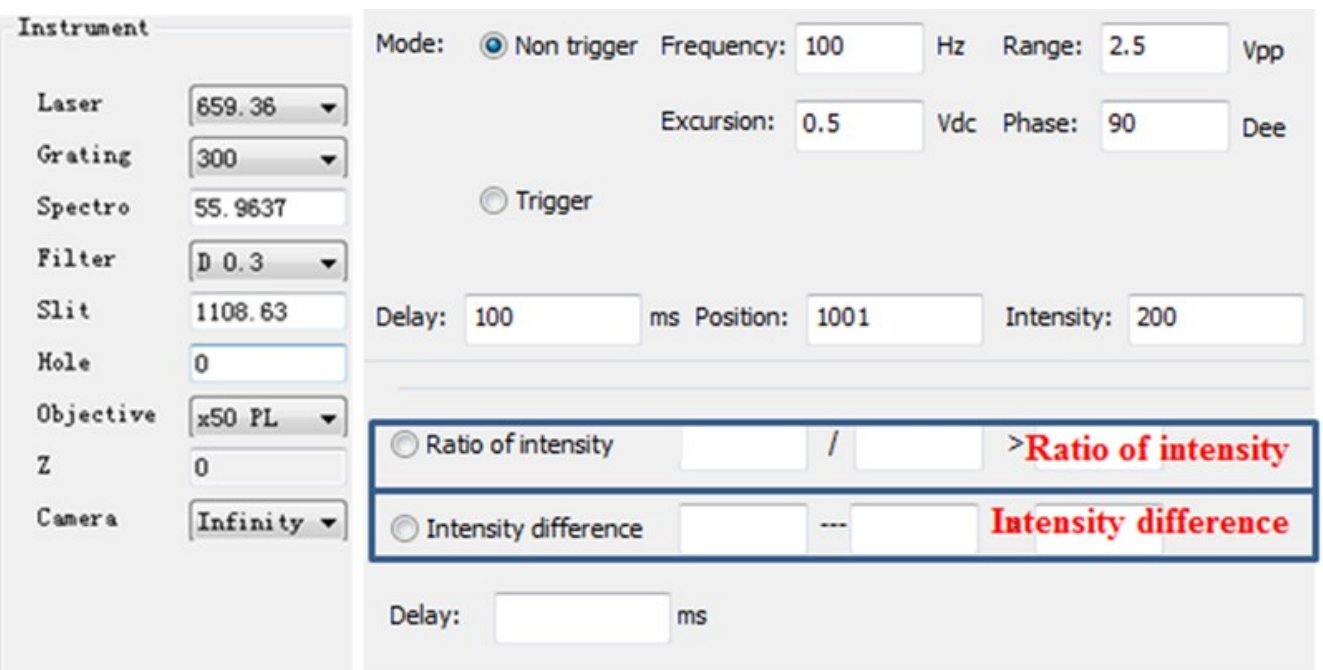

(B) 


\section{Figure 5}

The Framework of simulation system.

Figure 5: The Framework of simulation system.

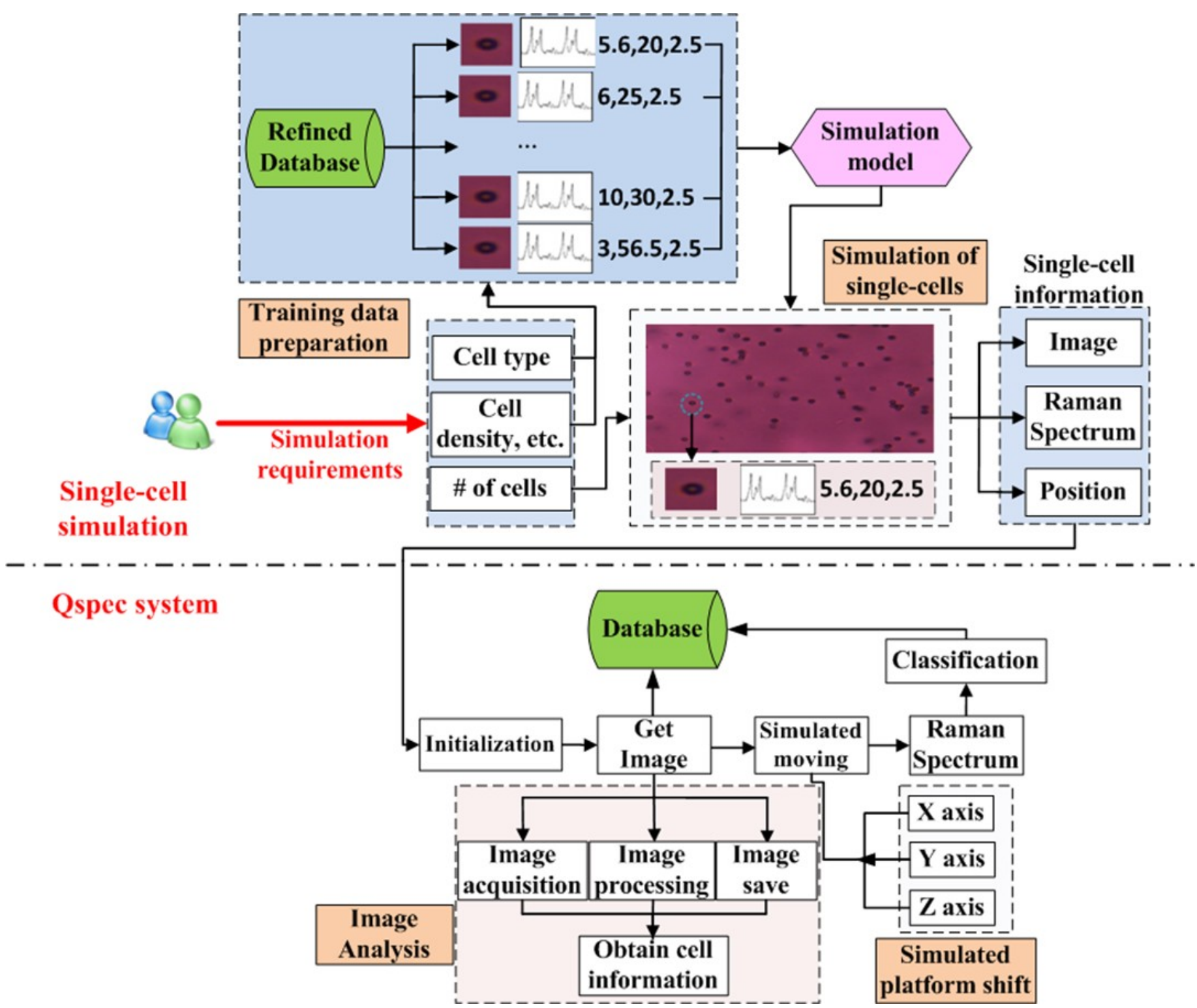




\section{Figure 6}

The comparison of Raman spectra obtained by un-normalized automatic and manual measurements.

Figure 6: The comparison of Raman spectra obtained by un-normalized automatic and manual measurements. $(A)$ and $(B)$ showed the Pearson correlations for all peaks measured by automatic (X-axis) and manual (Y-axis) methods for two single-cells. (C) and (D) showed the real Raman profiles measured by automatic (blue) and manual (green) methods for the two single-cells in (A) and (B), respectively.

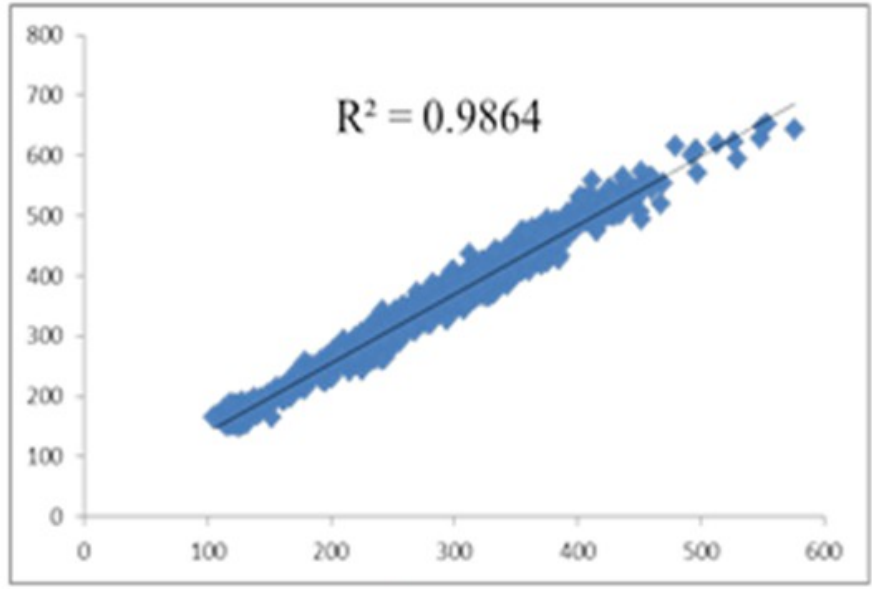

(A)

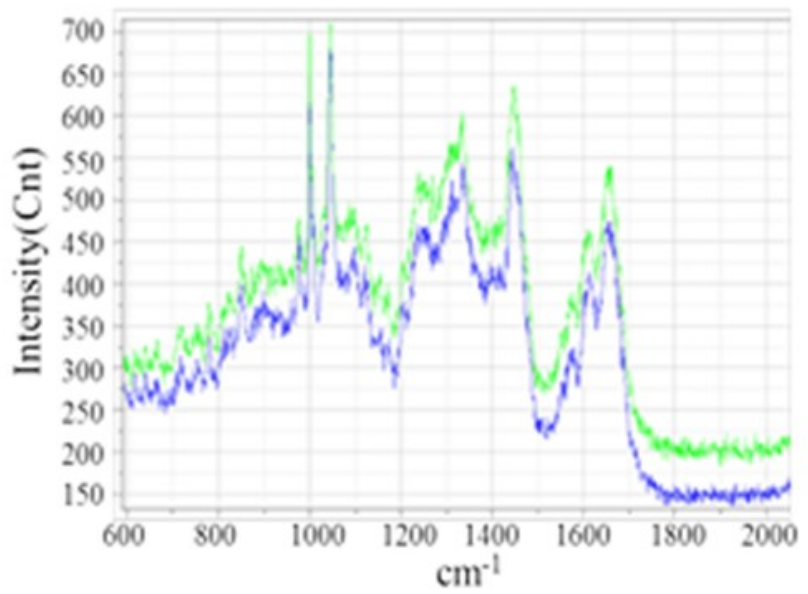

(C)

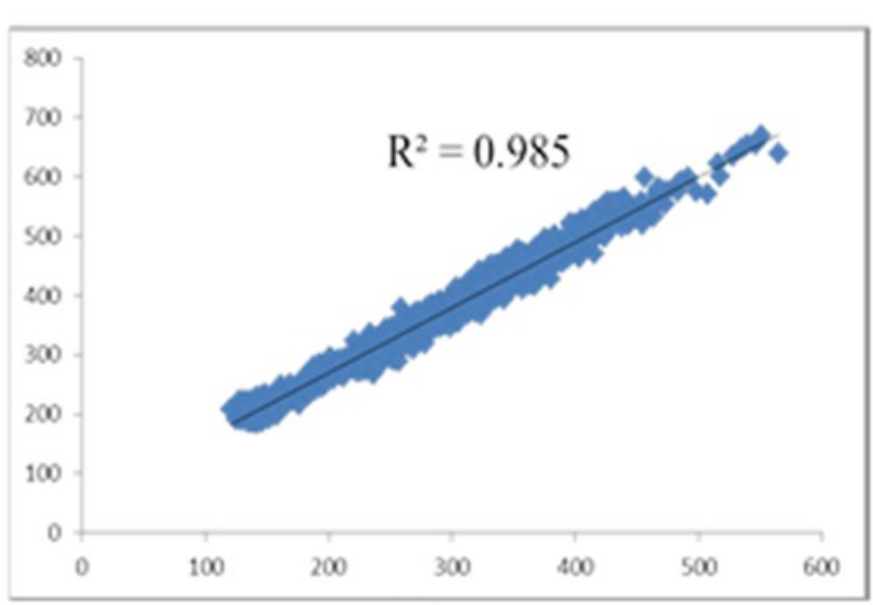

(B)

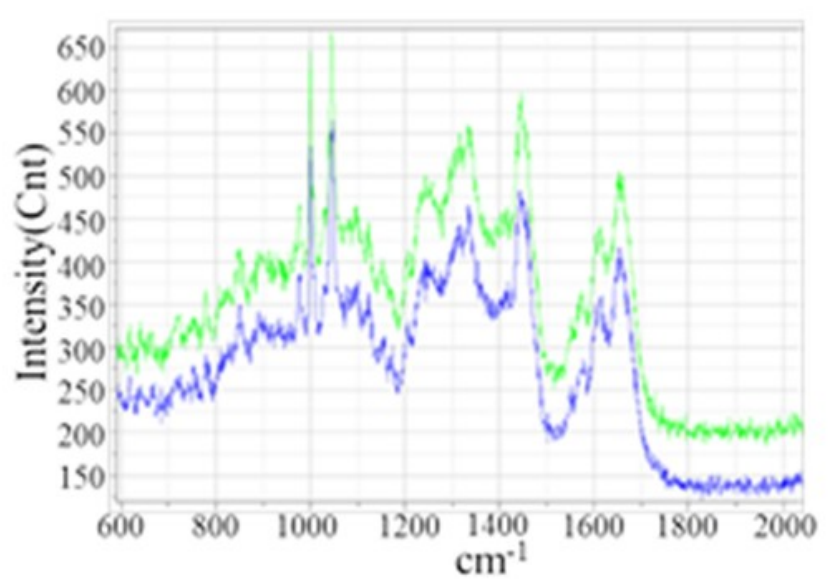

(D) 


\section{Figure 7}

The screenshot of QSpec analysis for Saccharomyces cerevisiae .

Figure 7: The screenshot of QSpec analysis for Saccharomyces cerevisiae. This window consists of six visible yeast cells/cell-clusters. QSpec has successfully acquired images and Raman spectra for five single-cells.

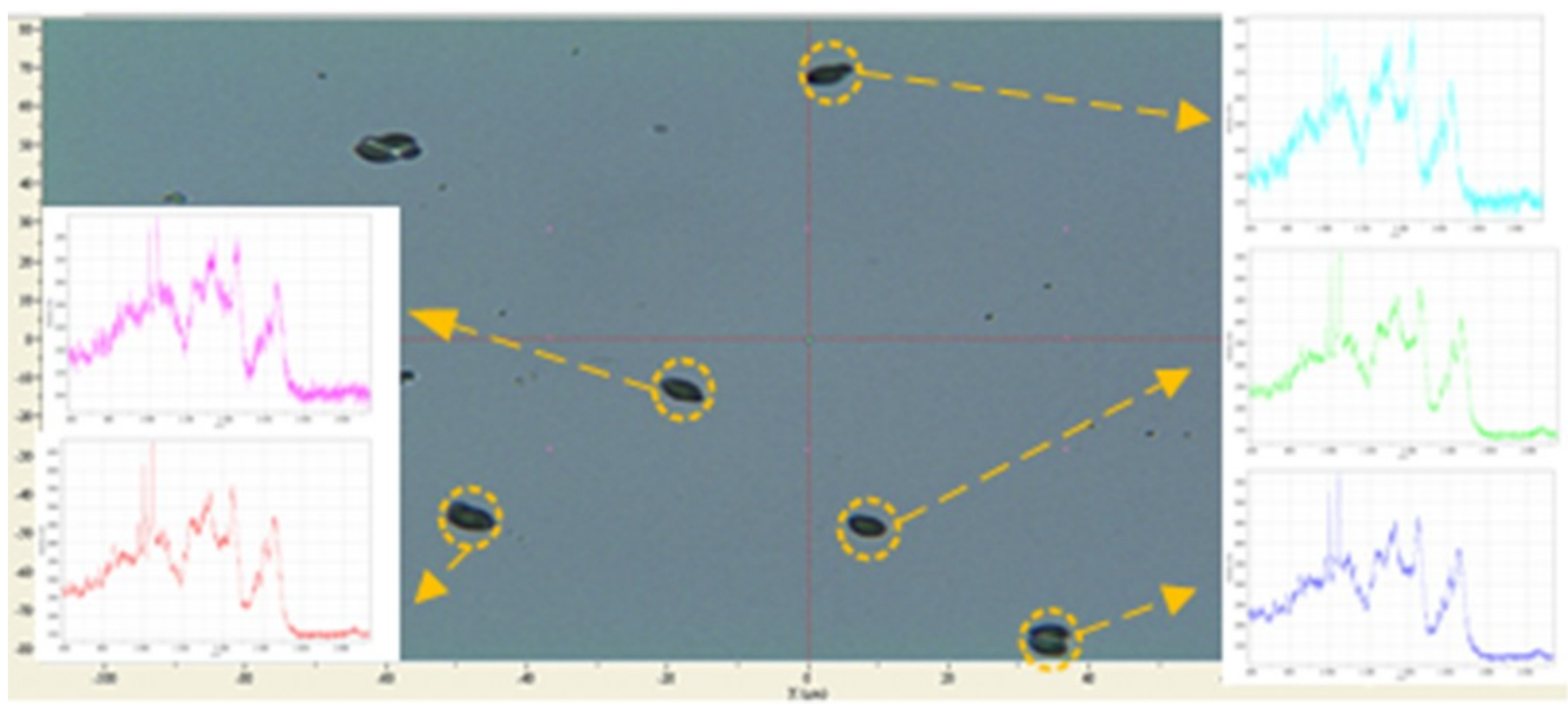




\section{Figure 8}

The prototype of the single-cell Raman profile database.

Figure 8: The prototype of the single-cell Raman profile database.

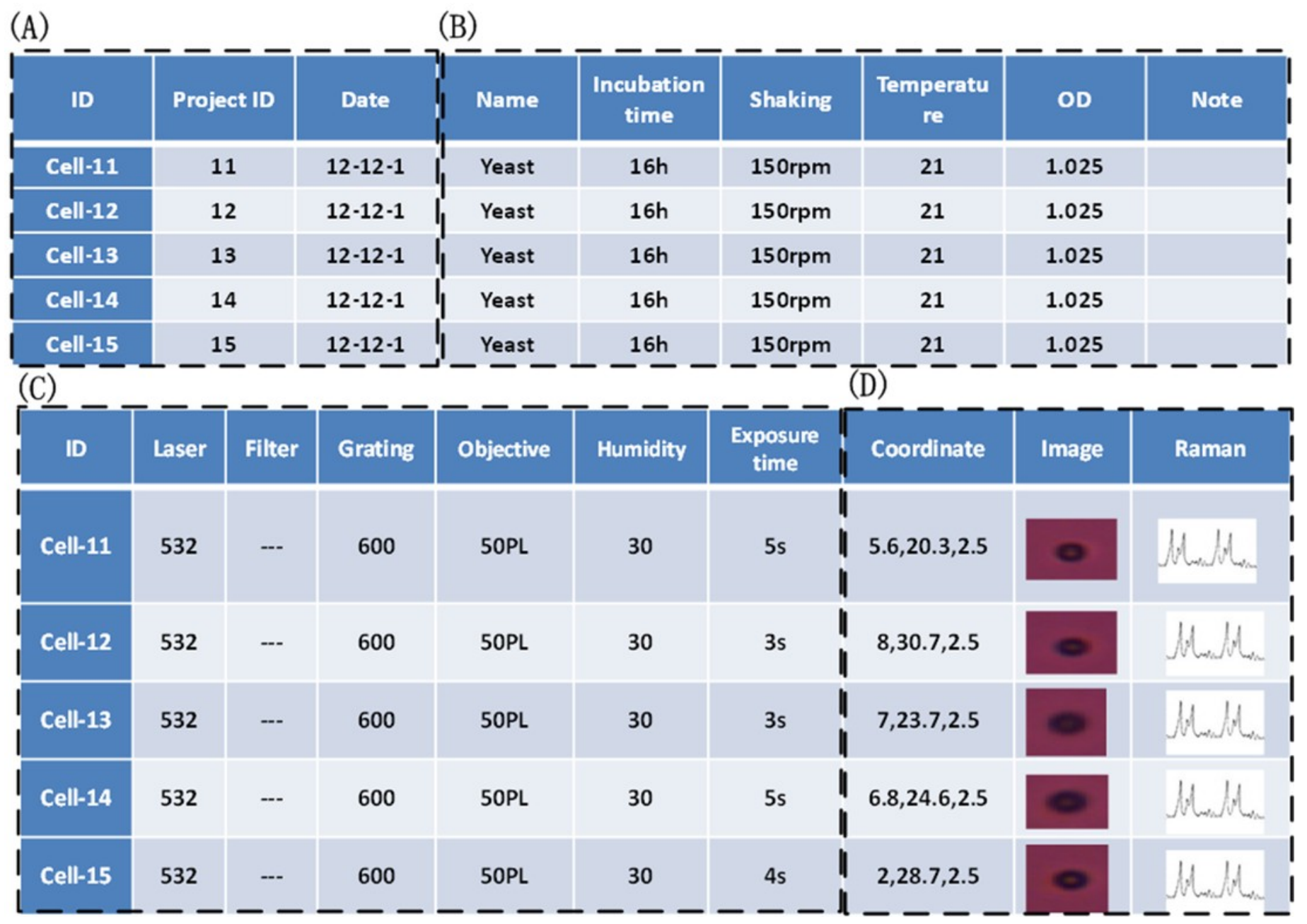




\section{Figure 9}

PCA analysis can clearly separate single-cells from different strains based on their Raman spectra in refined database

Figure 9: PCA analysis can clearly separate single-cells from different strains based on their Raman spectra in refined database.

$\nabla$ Staphylococcus aureus

ATCC6538

Staphylococcus epidermidis

ATCC 12228
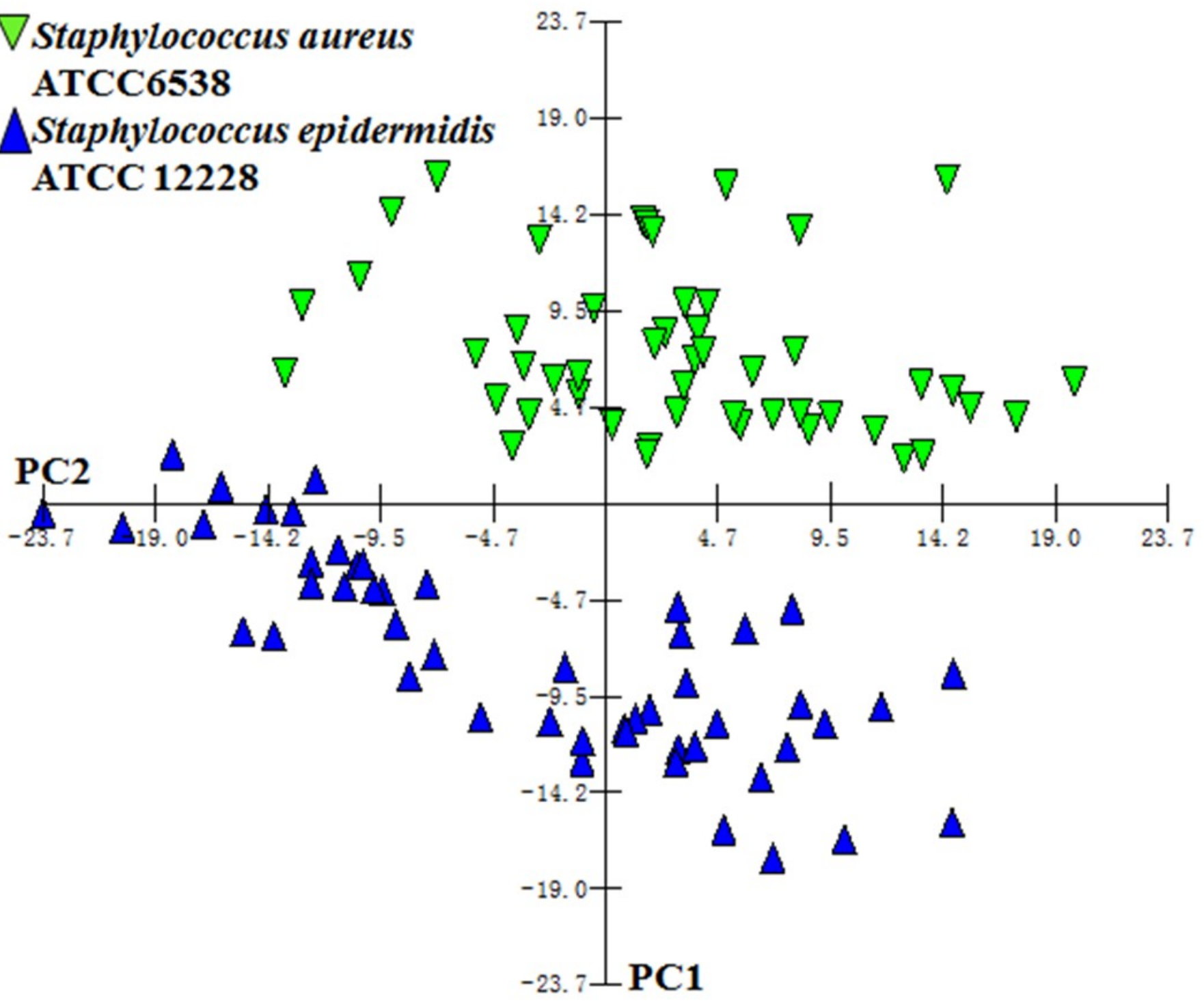


\section{Figure 10}

The comparison of (A) search accuracy and (B) search time based on SVM and Euclidean Distance methods.

Figure 10: The comparison of (A) search accuracy and (B) search time based on SVM and Euclidean Distance methods. Each data point represents the average numbers based on 20 query single-cells. 

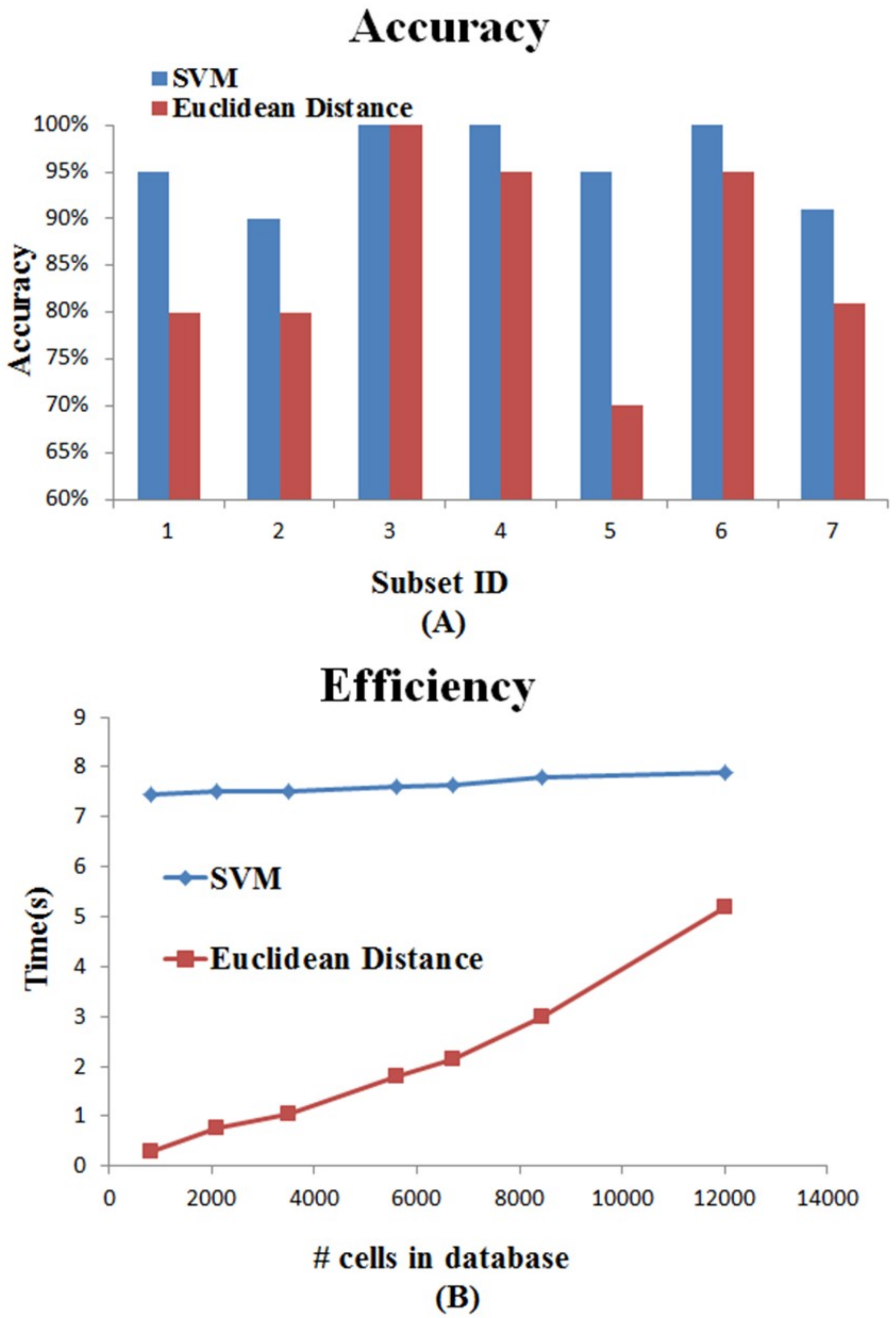


\section{Table 1 (on next page)}

Sensitivity of single-cell image and Raman spectrum extraction based on simulated dataset.

Table 1 : Sensitivity of single-cell image and Raman spectrum extraction based on simulated dataset. 
Table 1: Sensitivity of single-cell image and Raman spectrum extraction based on simulated dataset.

\begin{tabular}{lcccc}
\hline Simulated cell & $\begin{array}{c}\text { \# Cells } \\
\text { (window size } \\
\text { fixed) }\end{array}$ & $\begin{array}{c}\text { \# Correctly } \\
\text { recognized } \\
\text { cells }\end{array}$ & $\begin{array}{c}\text { Sensitivit } \\
\text { y of image } \\
\text { analysis }\end{array}$ & $\begin{array}{c}\text { Sensitivity } \\
\text { of Raman } \\
\text { profiling }\end{array}$ \\
\hline $\begin{array}{c}\text { Saccharomyces } \\
\text { cerevisiae }\end{array}$ & $100 * 5$ & 475 & $95.0 \%$ & $91.0 \%$ \\
$\begin{array}{c}\text { Saccharomyces } \\
\text { cerevisiae }\end{array}$ & $100 * 10$ & 956 & $95.6 \%$ & $95.0 \%$ \\
$\begin{array}{c}\text { Saccharomyces } \\
\text { cerevisiae }\end{array}$ & $200 * 5$ & 932 & $93.2 \%$ & $91.3 \%$ \\
$\begin{array}{c}\text { Saccharomyces } \\
\text { cerevisiae }\end{array}$ & $200 * 10$ & 1931 & $96.5 \%$ & $96.1 \%$ \\
\hline
\end{tabular}




\section{Table 2 (on next page)}

Accuracy for single-cell phenotype extraction based on yeast and bacterial cells under various test conditions.

Table 2: Accuracy for single-cell phenotype extraction based on yeast and bacterial cells under various test conditions. 
Table 2: Accuracy for single-cell phenotype extraction based on yeast and bacterial cells under various test conditions.

\begin{tabular}{ccccccc}
\hline Cell & Test & $\begin{array}{c}\# \\
\text { condition }\end{array}$ & $\begin{array}{c}\text { Cells correctly } \\
\text { recognized } \\
\text { cells after } \\
\text { image } \\
\text { analysis }\end{array}$ & $\begin{array}{c}\text { Sensitivity } \\
\text { of image } \\
\text { analysis }\end{array}$ & $\begin{array}{c}\text { \# correctly } \\
\text { recognized } \\
\text { cells after } \\
\text { Raman } \\
\text { profiling }\end{array}$ & $\begin{array}{c}\text { Sensitivity } \\
\text { of Raman } \\
\text { profiling }\end{array}$ \\
\hline $\begin{array}{c}\text { Saccharomyce } \\
\text { s cerevisiae } \\
\text { BY4743 }\end{array}$ & Tube & 115 & 82 & $71.3 \%$ & 48 & $41.7 \%$ \\
$\begin{array}{c}\text { Saccharomyce } \\
\text { s cerevisiae } \\
\text { BY4743 }\end{array}$ & Slide & 96 & 75 & $78.1 \%$ & 62 & $64.6 \%$ \\
$\begin{array}{c}\text { Streptococcus } \\
\text { sanguinis }\end{array}$ & Tube & 80 & 43 & $53.7 \%$ & 16 & $20.0 \%$ \\
$\begin{array}{c}\text { Streptococcus } \\
\text { sanguinis }\end{array}$ & Slide & 73 & 41 & $56.1 \%$ & 33 & $45.2 \%$ \\
\hline
\end{tabular}

